\title{
A meta model-based methodology for an energy savings uncertainty assessment of building retrofitting
}

\author{
Antoine Caucheteux ${ }^{1, *}$, Antoine Gautier ${ }^{2}$, and Rofaïda Lahrech ${ }^{3}$ \\ ${ }^{1}$ CEREMA, 23 av. de l'Amiral Chauvin BP 20069, 49136 Les Ponts de Ce Cedex, France \\ 2 SOLAMEN, 13 rue Dobre, 44100 Nantes, France \\ ${ }^{3}$ CSTB, 84 avenue Jean Jaures - Champs sur Marne, 77447 Marne la Vallee Cedex 2, France
}

Received: 26 April 2016 / Accepted: 13 September 2016

\begin{abstract}
To reduce greenhouse gas emissions, energy retrofitting of building stock presents significant potential for energy savings. In the design stage, energy savings are usually assessed through Building Energy Simulation (BES). The main difficulty is to first assess the energy efficiency of the existing buildings, in other words, to calibrate the model. As calibration is an under determined problem, there is many solutions for building representation in simulation tools. In this paper, a method is proposed to assess not only energy savings but also their uncertainty. Meta models, using experimental designs, are used to identify many acceptable calibrations: sets of parameters that provide the most accurate representation of the building are retained to calculate energy savings. The method was applied on an existing office building modeled with the TRNsys BES. The meta model, using 13 parameters, is built with no more than 105 simulations. The evaluation of the meta model on thousands of new simulations gives a normalized mean bias error between the meta model and BES of $<4 \%$. Energy savings are assessed based on six energy savings concepts, which indicate savings of $2-45 \%$ with a standard deviation ranging between $1.3 \%$ and $2.5 \%$.
\end{abstract}

Keywords: energy savings assessment / energy retrofitting / calibration / uncertainty analysis / building energy simulation / experimental design

\section{Introduction}

Within the framework of greenhouse gas emission reduction, the building sector represents about $40 \%$ of the global energy consumption of developed countries, and, within this percentage, existing building stock represents the main part of energy consumption. Energy retrofitting of this building stock presents significant potential for energy savings [1-3]. Building Energy Simulation (BES) can be a very helpful tool to propose adapted and optimized retrofitting measures [4]. In this paper, a method to analyze uncertainty and estimate the energy savings of retrofitted buildings is proposed. This method uses a BES model and is based on a meta model that is constructed using an experimental design. The method has been applied to a non-insulated commercial building that has been monitored for one year. First, some vocabulary related to models and simulations should be clarified. The word "model" could stand for analytical models that represent physical phenomena calculated based on mathematical equations (for example, thermal transfer through materials, aeraulic exchanges, etc.). These equations are coded in a computer program and constitute the founding principles of BES programs. Many of these programs do not allow the modification of

\footnotetext{
* Corresponding author: Antoine.caucheteux@cerema.fr
}

equations. Another kind of model is the construction of a representation of the building in the simulation program. This is a geometric, material or aeraulical description of the building. Then the simulation results from combining the building's numerical model and the physical models. In this paper, when we refer to models (without providing any details), the term will refer to both building and analytical models. The term simulation will refer to the results of calculations, taking into account model and variable inputs that are necessarily used by the program. As a consequence, a building simulation uses three different kinds of input data:

- constants that correspond to physical models (specific air heat, Stefan Bolzmann constant, etc.);

- static ones that correspond to building characteristics (dimensions, materials used, system characteristics, etc.); - dynamic ones that are needed for simulation runs (meteorological conditions, occupancy, indoor temperature, etc.).

Second, the energy performance evaluation should require measurements. In metrology, a measurement can be defined as the application of chains of traceability, in practice linked to measurement standards; we also speak of a reference. For example, the European Union defines energy performance as "the calculated or measured amount of energy needed to meet the energy demand associated with a typical use of the building, which includes, energy 


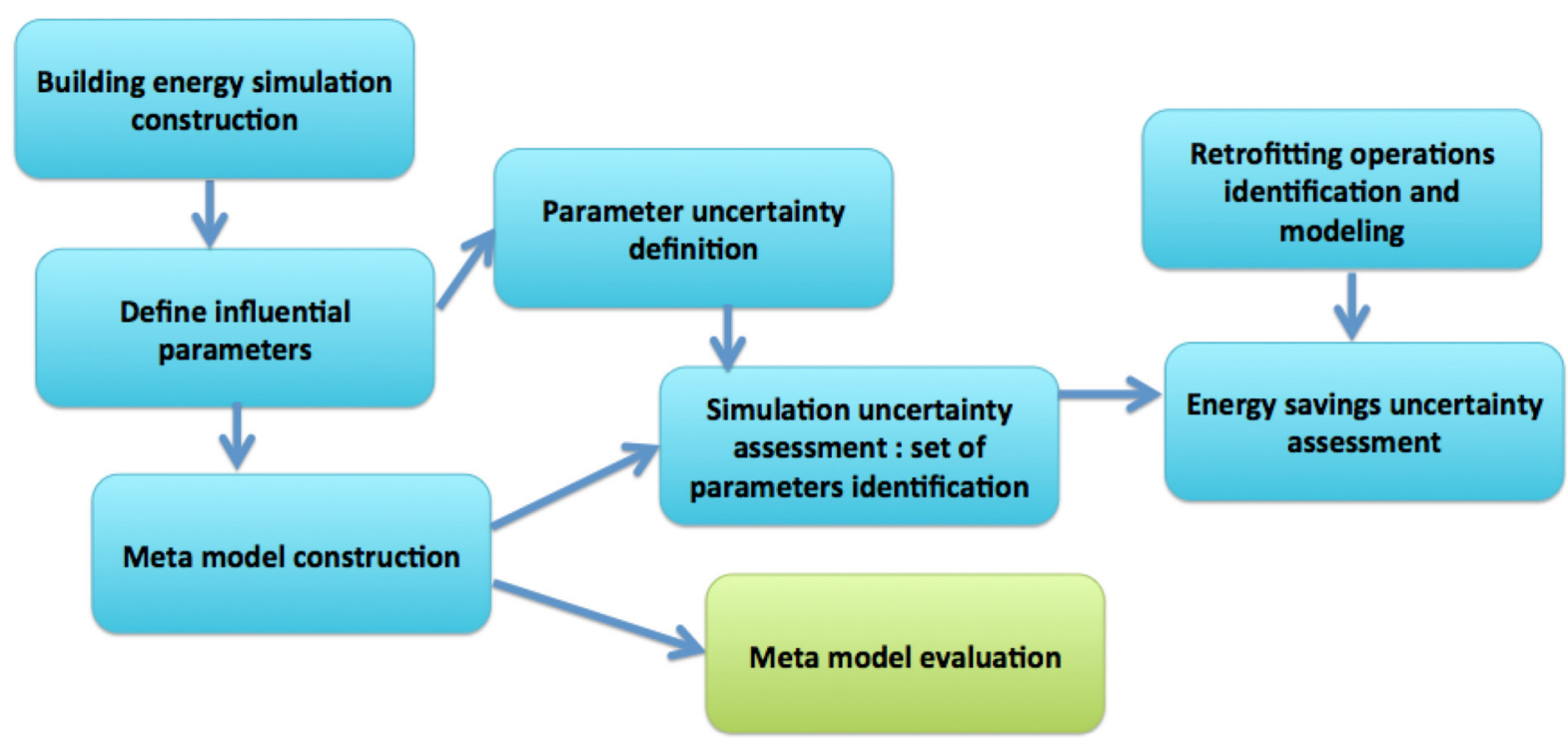

Fig. 1. Flowchart of the meta model-based approach to energy savings uncertainty assessments in retrofitted buildings.

used for heating, cooling, ventilation, hot water and lighting" [5]. In order to assess the energy performance of a building, some questions have to be asked:

- What is the typical use of a building?

- Which use of energy has to be considered?

For example, French Regulation [6] defines performance as the energy consumption of a building under standard (or conventional) meteorological conditions and occupancy. Occupancy is defined as the amount internal gains[6]. Energy consumption takes into account the five uses of energy: heating, cooling, hot water, lighting and auxiliaries. BES tools are then used to put the building under reference conditions. The first step is to make sure that the BES corresponds to reality; this is the calibration. In order to assess energy savings, simulation is used to compare building energy performance before and after retrofitting. The precision of this assessment depends on the precision of the calibration. BES calibration deals with finding the input data that represents the real building the most accurately and its energy performance in terms of the output data. But as results of the simulations are influenced by a high number of variables, it is still difficult to provide an accurate representation of a building's energy performance [7-10]: this is a highly under-determined problem [7,9] that leads to several plausible solutions. Consequently, in general, thousands of simulations are required, which is time-consuming and not practical from an industrial point of view using classical BES tools. Some authors use meta models [11-13] that are simplified, useful models and could run in a fraction of a second. Two techniques may be used. The first one, called model reduction, is based on the simplification of the mathematical description $[14,15]$. "Model reduction means generally to simplify a given mathematical description in such a way that output calculated by the reduced model does not differ very much from the original model." [14] The second one, called meta model, can also be broken down into two parts [7]:

- predefining a simplified mathematical equation (polynomial) and finding the coefficient to match a simplified model with the BES;

- the second one, called a black box, uses mathematical methods (like regression) to find the mathematical representation of the BES behavior itself.

The meta model construction still demands thousands of simulations but it should be constructed at the same time than the uncertainty analysis. The meta model should then be used to run tens of thousands of calculations to find an optimal set of parameters.

\section{Approach}

Ma et al. [16] explains that building energy retrofitting operations could impact four targets:

- reduce demand for heat;

- improve HVAC efficiency;

- modify human behavior;

- integrate new and renewable energy.

Among these four targets, Ma et al. [16] explains that the most efficient target from an environmental point of view is to reduce heat demand. Then, in this work, the calculated BES output data of interest in is heat demand. It is different from energy consumption as it corresponds to the heat which is needed to comply with a setpoint temperature in the building. It does not take into account the way this heat is produced. The flowchart for the method is presented in Figure 1. The blue box represents the operational method's steps, the green one is only for method evaluation and is optional from an practical point of view.

The following sections describe in detail each step. 


\subsection{BES construction}

There are several tools to construct an energy simulation (TRNsys, Energy plus, etc.). These tools offer a wide selection of modeling types with the possibility to take into account (or not) different physical models such as:

- obviously, thermal transfers;

- hygrothermal transfers;

- number of zones in the building;

- aeraulical transfer (ventilation, infiltrations, etc.);

- solar protection of the building, etc.

The construction of the building energy model should then be time-consuming depending on the number of parameters and phenomena taken into account. This would influence the accuracy of the simulation, which is also affected by the static data collection (audit).

\subsection{Define influential parameters}

The second step is to identify the uncertain parameters which should have the most influence on BES results. From an operational perspective, it is not possible to perform thousands of simulation for all parameters because it is too time-consuming. The goal of the method is to select these parameters by analyzing the literature and on the basis of choices made in the simulation construction and the audit. A sensitivity analysis is usually used to classify parameters as a function of their influence on the results. It could take into account thousands of parameters in the simulation, but most of the time it is reduced to hundreds, for example. From these hundreds [17], only about 10-20 finally represent the main influences on results $[7-9,17]$. Most of the time, the parameters to which the simulations are the most sensitive, also present the strongest interactions with one another. Manfred [12] classified parameters into 12 groups:

- climatic conditions and location;

- envelope;

- activities: occupancy, process (gain and schedules);

- lighting: power, control, schedule;

- control and operation (including temperature setpoint, ventilation and heating/cooling);

- water loop (pump, pipes, etc.);

- air loop (length, insulation);

- air handling units (temperature of fluids, humidification, fans, pump);

- terminal units (emission temperature, efficiency);

- domestic hot water;

- plant (heating and cooling generation, efficiency, etc.);

- distributed generation.

Seven of these groups of parameters relate to HVAC, so, when focusing on heat demand, it is possible to reduce the number of groups to only five. The literature [12,13,18-22] provides some guidance for the selection of parameters in each group:

- temperature setpoint when selected (and schedule);

- internal gains (through presence of people, lighting and plugs or appliances: schedule and values);

- thermal characteristics of the walls, roof and floor (coefficient of conduction $/ \mu$ );
- characteristics of the windows $(U$ and $g$ );

- ventilation and infiltration rate;

- meteorological conditions (mostly temperature).

Some of the parameters seems to be less important: albedo, wall absorption and emission, coefficient of convection, orientation, dimensions, etc. Then with a bibliographical analysis, an experienced operator should predefine the potential most influential variables.

\subsection{Meta model construction/calculation}

The first step in this method is to run a simulation to construct the meta model. A meta model is often constructed by matching a predefined equation to a monitoring value [23]. The use of experimental design tools allows for the optimization of the number of simulations to run and avoid the use of fitting algorithms. In this paper, the construction of a meta model is proposed not only for the entire year, but also on a daily basis. It should then allow for a more precise meta model to be reached and the use of indicators such as CVRMSE, as recommended by ASHRAE [10].

Experimental design methods are mathematical sets of tools that enable the establishment and analysis of the relationship between one or more variables and the parameters that make them vary. This can be used for optimization strategies [24]. Moreover, it could be used to obtain a simplified representation of a phenomenon. In our case, it could represent the demand for building heat as a function of a reduced number of parameters. For each $\mathrm{Pi}$ parameter, upper (1) and lower (0) limits are set in accordance with the field under study. The response is considered to be linear between these two values. Let $P i$ be the real value of the parameter $i$ (for example insulation thickness) and $P i^{*}$ the corresponding value of the parameter in the experimental design (between 0 and 1 ). For a linear-dependent parameter $P i$, if the range of variation is from min to $\max$, the $P i^{*}$ is calculated from equation (1):

$$
P i^{*}=\frac{P i-P i_{\min }}{P i_{\max }-P i_{\min }}
$$

Otherwise, if, for example, the thickness of insulation is considered an influential parameter, with a range of variation of $\left[P i_{\min }, P i_{\max }\right]$, the heating load is reversibly thickness-dependent. The $P i^{*}$ parameter is then defined as shown in equation (2):

$$
P i^{*}=\frac{1 / P i-1 / P i_{\max }}{1 / P i_{\min }-1 / P i_{\max }} .
$$

Then the number of experiments that must be conducted depends upon the number of parameters chosen and their interaction. The variable we are interested in is heating load. For each experiment $(k)$ the BES daily consumption $C_{\text {calc, } d, k}$ is calculated, where $d$ corresponds to the day's number and $k$ the experiment number. The purpose is to write the equation of the calculated consumption for each day $(d)$ of calculation and for each experiment $(k)$ as a function of the parameter values. 
Table 1. Example of a two-parameter experiment design.

\begin{tabular}{llllll}
\hline & $P 1^{*}$ & $P 2^{*}$ & $P 1^{* 2}$ & $P 2^{* 2}$ & $P 1^{*} P 2^{*}$ \\
\hline E0 & 0.5 & 0.5 & 0.25 & 0.25 & 0.25 \\
E1 & 1 & 0 & 1 & 0 & 0 \\
E2 & 0 & 1 & 0 & 1 & 0 \\
E3 & 0.5 & 0 & 0.25 & 0 & 0 \\
E4 & 0 & 0.5 & 0 & 0.25 & 0 \\
E5 & 1 & 1 & 1 & 1 & 1 \\
\hline
\end{tabular}

For example, if we take into account two parameters, $P 1$ and $P 2$, we can build the design of the experiment presented in Table 1. The first line corresponds to experiment E0 which is the first experiment, where every parameter is in the center of the parameters' range of variation. The following experiments deal with a parameter's influence (first or second degree) or interaction between the two parameters (which is considered second degree). The design of experiments is constructed in order to obtain an invertible matrix. The degree of the experimental design corresponds to the order of the polynomial.

Then we can write the daily heating load as shown in equation (3):

$$
\begin{aligned}
C_{d, k} & =\alpha_{d, 0}+\sum_{d, i} * P i^{*}+\sum \alpha_{d, i, i} * P i^{* 2}+\alpha_{d, 1,2} \\
& * P 1^{*} * P 2^{*}
\end{aligned}
$$

with $P i^{*}$, the parameter values, $\alpha_{d, 0}, \alpha_{d, i}, \alpha_{d, i, i}$ and $\alpha_{d, 1,2}$ are the coefficients of the equation. More generally, let $C_{\text {calc, } d}$ be the vector of the calculated consumption for each experiment on Day $d$, and $P$ the matrix of the $P i$ value. It yields (Eq. (4)):

$$
C_{\text {cacl }, d}=M_{d} * P,
$$

where $M_{d}$ is the vector of coefficient $\alpha$. With experimental design, it is possible to identify $M_{d}$ if $P$ is an invertible matrix (if its determinant is not null). It yields as many matrix $M_{d}$ as monitored days. The coefficients provide the uncertainty indices.

The evaluation of the meta model will be set out in this paper in Section 3.3. It consists in making a subsequent number of BES calculations with the random value of each parameter of interest and comparing meta model results with BES results.

\subsection{Definition of parameter uncertainty}

Parameter uncertainty refers to both statistical distribution and the range of uncertainty for each influential parameter (measured or not). Defining the range of uncertainty of a parameter is quite difficult. Indeed, it depends on many things: has the measurement been conducted? What is the sensor uncertainty? What is the uncertainty of the method used?, etc. Substantial research is conducted to reduce the uncertainty of input parameters.
As pointed out by ASHRAE and IPMVP [10,25], one of the keys to building energy efficiency verification is to control the uncertainty of the data measurement of all the parameters measured (influential or not) as efficiently as possible. Nevertheless, it is possible to find keys in the literature. For example, it is acknowledged that the temperature uncertainty could follow a Gaussian distribution with a standard deviation of $1 \mathrm{~K}$ [21]. For some static parameters, the audit and operator's judgment should determine the uncertainty as a function of the quality of the measurement (if it has been taken or not) and the degree of knowledge on the parameter. When a parameter cannot be measured or when the distribution is unknown, it is common to use uniform distribution.

\subsection{Simulation uncertainty assessment and keys for calibration}

Calibration consists in comparing measured and calculated data. This process is iterative and tends to improve the building model (making it the most life-like). It consists in modifying the input data until having the simulation calculation results correspond to the greatest extent possible to the data measured.

In order to analyze the differences between measurements and calculations and to evaluate the uncertainty of the simulation, ASHRAE [10] proposes two main indicators: the Normalized Mean Bias Error (NMBE) and the Coefficient of Variation of the Root Mean Square Error (CVRSME) as described in equations (5) and (6)

$$
\begin{gathered}
\mathrm{NMBE}=100 \times \frac{\sum m_{i}-s_{i}}{(n-1) \times \bar{m}}, \\
\mathrm{CVRMSE}=100 \times \frac{\sqrt{\Sigma\left(m_{i}-s_{i}\right)^{2}}}{\sqrt{n-1} \times \bar{m}},
\end{gathered}
$$

where $m_{i}$ and $s_{i}$ are measured and simulated values for each $i$ data point, and $n$ being the number of data points. $\bar{m}$ is the average of measured values. CVRMSE could refer to different time steps. Most of the time, time steps are months or hours, but equations could be used for any time step such as a day or a week. Finally, ASHRAE considers that a BES model is calibrated when "they produce NMBEs within $10 \%$ and CVRMSE within $30 \%$ when using hourly data or $5-15 \%$ with monthly data" [10]. With this method, thousands of meta model calculations are performed with random parameter values in their range of variation. Combinations of parameters that fulfill acceptable criteria (for example, NMBE $<5 \%$ and CVRMSE $<15 \%$ ) are retained for further analysis.

\subsection{Energy savings uncertainty assessment}

Energy retrofit strategies use a combination of basic energy saving techniques. In the context of the methodology presented, which targets heat demand, energy saving techniques focus on the improvement of the energy characteristics of the building envelope (for example 


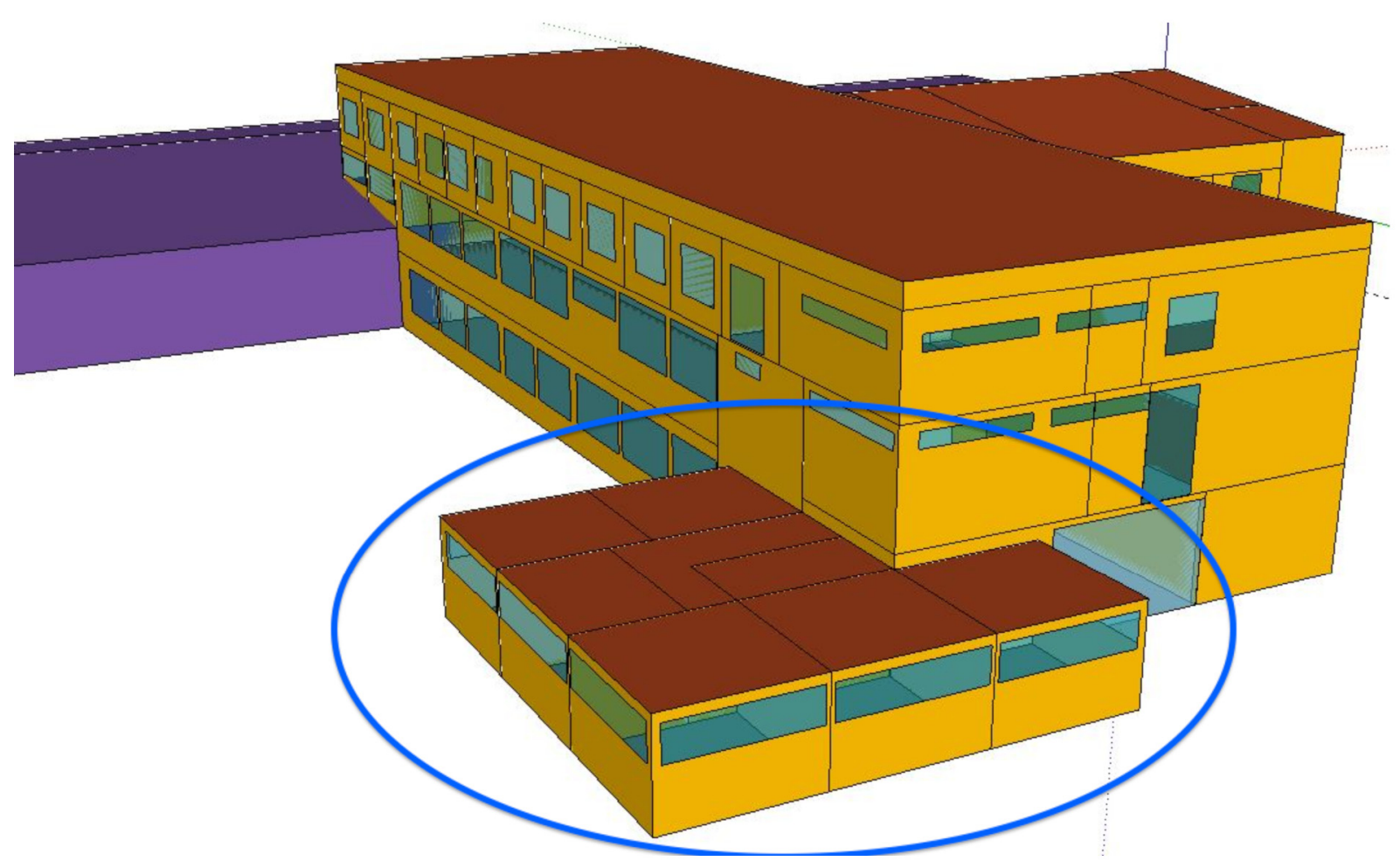

Fig. 2. Sketchup 3D representation of the monitored building.

windows substitution, roof of wall insulation, etc.). The first step is obviously to define basic retrofit measures to apply to the building, from which series of tasks was defined: this is energy retrofit strategies. Several strategies may be designed. Each one must be modeled in the same simulation tool that was used previously. The next step is to construct a meta model for the retrofitted building. It has the same structure than the one for the existing building: the same parameters with the same uncertainty must be used. The equation must be in the same order as well. Then it uses the same experimental design. When a basic retrofit measures involves one of the meta model's parameters, it is assumed that there is no more uncertainty for the parameters.

Now, there is a meta model for the initial building and one meta model for each energy retrofit strategy. In order to assess energy savings and their uncertainty, the following describes the steps for a selected number of tests (for example, 10000):

Randomly choose a combination of the initial parameters in their range of variation following the uniform distribution:

- calculate simulated heat demand of the initial building; - compare this to the monitoring results;

- if it meets the criteria, retrofit heat demand is calculated for all the retrofit strategies;

- finally, the energy savings are calculated for each strategy.

In conclusion, it is possible to draw the density plot of energy savings for each strategy: this provides an average value and a standard deviation, which is the uncertainty.

\section{Case study}

\subsection{Building and model}

Part of a commercial building in Angers (France) was monitored (Fig. 2). It is an area of $105 \mathrm{~m}^{2}$ made with blocks without insulation, built in the seventies. Insulation was added to the suspended ceiling in the nineties. The windows are composed of double panes $(4 / 6 / 4)$ with an aluminum frame. There is controlled mechanical ventilation with a single flow system. Heating is provided through a conventional hightemperature waterloop system with a condensing boiler.

Around 100 sensors were deployed through this area. Monitoring was set up at the end of 2012. One year of monitoring data (2013) is available. The monitoring time interval is $5 \mathrm{~min}$, which was transformed into $1 \mathrm{~h}$ time intervals for the simulation. Temperature sensors were placed in each room at about $1.5 \mathrm{~m}$ high on an inside wall, far from windows and doors. Heat demand was monitored with an ultrasound calorimeter which was installed on the space heating waterloop at the entrance to the area. Due to its position, we believe that the energy monitored is used entirely for space heating: heat distribution losses are all recuperated. The discretization is $1 \mathrm{kWh}$, which gives an equivalent daily uncertainty.

Occupancy was also monitored. For the complexity of occupancy monitoring, we chose to measure the following parameters [26]:

- presence of occupants;

- status of artificial lighting (on/off);

- windows state;

- plug loads. 
Table 2. Choice of parameters and the way they vary.

\begin{tabular}{lllcc}
\hline DoE coding & Parameter & Way of variation & Min & Max \\
\hline P1 & Indoor temperature setpoint $(\mathrm{K})$ & Addition & -1 & +1 \\
P2 & Ventilation rate $\left(\mathrm{m}^{3} / \mathrm{h}\right)$ & Rate & 100 & 200 \\
P3 & Airtightness $\left(\mathrm{m}^{3} / \mathrm{h} \mathrm{m}^{2}\right)$ & Average airtightness multiplication & 0.5 & 2 \\
& & coefficient & & \\
P4 & Glass solar transmittance & Multiplicative coefficient & 1.2 & 0.8 \\
P5 & Wall air gap thermal resistance $\left(\mathrm{m}^{2} \mathrm{~K} / \mathrm{W}\right)$ & Value & 0.23 & 0.11 \\
P6 & Roof insulation conduction coefficient $\left(\mathrm{W} / \mathrm{m}^{2} \mathrm{~K}\right)$ & Multiplicative coefficient & 1.2 & 0.5 \\
P7 & Plug loads $(\mathrm{W})$ & Multiplicative coefficient & 2 & 1 \\
P8 & Occupancy $($ employee presence $)$ & Multiplicative coefficient & 2 & 1 \\
P9 & Windows conduction coefficient $\left(\mathrm{W} / \mathrm{m}^{2} \mathrm{~K}\right)$ & Value & 4.2 & 3.2 \\
P10 & Linear conduction coefficient $(\mathrm{W} / \mathrm{mK})$ & Multiplicative coefficient & 1.2 & 0.8 \\
P11 & Floor concrete thichness $(\mathrm{m})$ & Value & 0.3 & 0.2 \\
P12 & Albedo & Value & 0.4 & 0.1 \\
P13 & Ground temperature $(\mathrm{K})$ & Addition & -3 & +3 \\
\hline
\end{tabular}

Several solutions can be used for each parameter. The final choice is:

- a passive infrared (PIR) motion detector for presence;

- luminance for lightning;

- door and window status detectors;

- electricity consumption for plug loads.

During the one-year monitoring period, there were periods when data went missing due to technical reasons. Then, for calibration, we reduced our period of analysis to the first 77 days (from January 1 to March 19). In order to model this building, TRNsys v17 [27] with Type 56 [28] were used for heat transfer calculations. Zones were defined corresponding to offices and corridors temperature measurements (see "monitoring" further below). TRNsys and Contam [29] are coupled for air flow modeling. The model includes mechanical ventilation, infiltration and door and window opening. When air tightness was measured, it was often observed that most of the air leaks occurred around the windows. So for the modelization, the infiltration leaks were distributed not only proportionally to wall dimensions but also taking into account the number and quality of the windows. Plug loads were estimated based on the monitoring of electrical consumption that corresponds to the use of specific electricity and artificial lighting. The presence of people was considered to be "seated and working people". A strong non-destructive audit was carried out on all of the characteristics of the building. The simulation provides the heat demand for each zone. A simulation takes about $26 \mathrm{~min}$ on a standard office computer (Intel Core i3-2330M with 4 Go RAM).

\subsection{Parameters of interest and their uncertainty}

As described above, the choice of influential parameters to be varied was based on a review of the literature, monitoring choices and the result of the audit. Thirteen parameters were selected. Table 2 presents the parameters and their range of variation.
The first parameter that is identified as one of the most influential in building simulation results is the temperature setpoint $[17,21]$. The indoor temperature was monitored for each thermal zone that corresponds to the BES setpoint temperature. It is considered a systematic uncertainty of $+/-$ one degree on measured data. This takes into account both sensor uncertainty and spatial uncertainty. The chosen distribution is Gaussian.

The ventilation rate was measured with an airflow cone and hotwire anemometer. The measurement reads $150 \mathrm{~m}^{3}$ per hour. This kind of measurement usually presents about $5 \%$ of uncertainty but measurement conditions led us to select values between 100 and $200 \mathrm{~m}^{3}$ per hour, which corresponds to a Gaussian distribution with an average value of 150 and a standard deviation of 25 .

The air tightness coefficient was taken at $1.7 \mathrm{~m}^{3} / \mathrm{h} \mathrm{m}^{2}$, which is the default value for existing buildings. The typical variation observed led us to apply a multiplicative coefficient variation from 0.5 to $2[30]$ with uniform distribution.

Glass solar transmittance varied independently from the windows' conduction coefficient. The windows are double-paned $(4 / 6 / 4)$ with an aluminum frame. The initial value of the modelized windows chosen was $g=7 \%$. The distribution chosen was uniform distribution.

The wall conduction coefficient varies in accordance with the air gap between concrete blocks and gypsum panels which range, according to French regulations between 0.11 and $0.23 \mathrm{~m}^{2} \mathrm{~K} / \mathrm{W}$, with uniform distribution.

The roof conduction coefficient varies in accordance with the thickness of insulation, but in order to have a linear effect on calculation, the thermal conduction coefficient was made varying with a multiplication coefficient from 1.2 to 0.5 . It was not measured so a uniform distribution was applied.

As many dynamic parameters measurements were monitored, there is a low uncertainty as to schedules. For plug loads and presence monitoring, it is assumed that there is an underevaluation. For example, PIR detectors 
should not detect a non-moving person. Or it should detect only one person when there are many. Then a multiplicative coefficient uniform variation from 1 to 2 is applied.

The window conduction coefficient $(U w)$ selected was from 3.2 to $4.2 \mathrm{~W} / \mathrm{m}^{2} \mathrm{~K}$, with uniform distribution.

The linear conduction coefficients between vertical and horizontal walls vary with a multiplication coefficient of around a standard value $(0.263 \mathrm{~W} / \mathrm{mK})$ with uniform distribution from 0.8 to 1.2 .

There is a great uncertainty in the floor composition. As the building was built before the first oil crisis in the 70s, it may be composed of concrete without insulation. The conduction coefficient varies in accordance with the thickness of the concrete between 20 and $30 \mathrm{~cm}$, with uniform distribution.

The albedo varies between 0.1 and 0.4 , with uniform distribution.

As in the model, ground temperature is considered as constant; it ranges between $-3 \mathrm{~K}$ and $+3 \mathrm{~K}$, with uniform distribution.

Table 2 summarizes the parameter range, "Min" corresponds to the parameter value that minimizes the heat load calculation results.

\subsection{Initial building meta model construction and evaluation}

For the meta model construction, it is used TRNsys simulations over one-year period. It uses monitoring datas. The missing values have been filled by means of statistical approach for building inside behaviour (temperature set points, internal gains, occupancy, etc.). For meteorological datas, the filled values comes from other building measurements in the same city.

A complete linear Design of Experiment (DoE) with the 13 parameters previously chosen leads to $2^{13}=8192$ experiments, considering all interactions between parameters (full order). As this is still too much, a second order is considered. It led to no more than 105 experiments. In order to optimize the number of experiments, the performance of a first order DoE was analyzed. Indeed, the 14 first experiments of second order DoE are the experiment of the first order DoE, it does not need any additional simulation.

A personal computer with eight cores was used. It allowed to perform six simulations at the same time. The 105 simulations were completed in about seven and a half hours. A DoE representation of daily consumption for each day of the year was calculated.

In this paper, a step is added in order to validate the method. Then, for the precision of the meta model evaluation, 1140 additional TRNsys simulations were run over a one-year period. For each simulation, random parameter values were taken from the uniform distribution in their range of variation. Calculations with the meta models were performed with the same parameter values. Then, for each simulation, NMBE and CVRMSE were calculated as described above (Eqs. (5) and (6)). As the meta model uses daily consumption, equations (5) and (6) have been applied with a daily time step (CVRMSEd). $m_{i}$ was considered as the meta-model calculation value and $s_{i}$ as the TRNsys daily simulation value. Figures 3

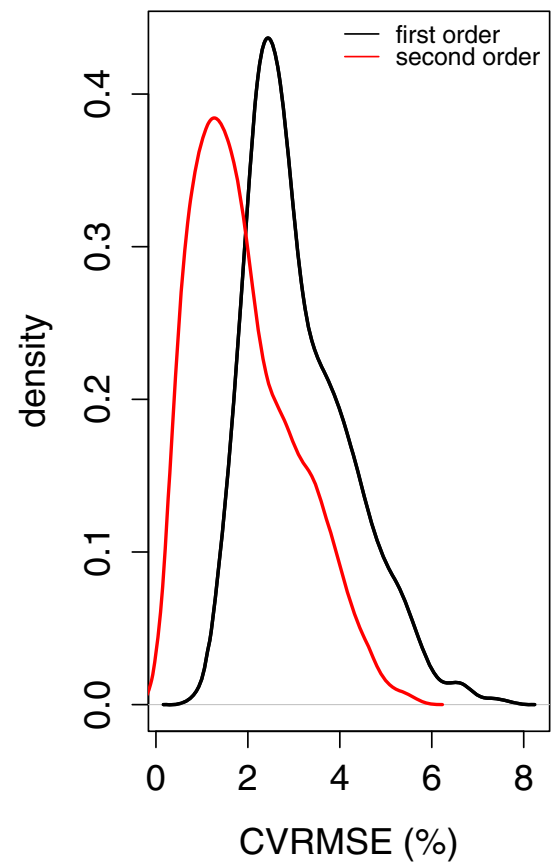

Fig. 3. BES vs. meta model: CVRMSEd ${ }_{\mathrm{BES}, \mathrm{Mm}}$.

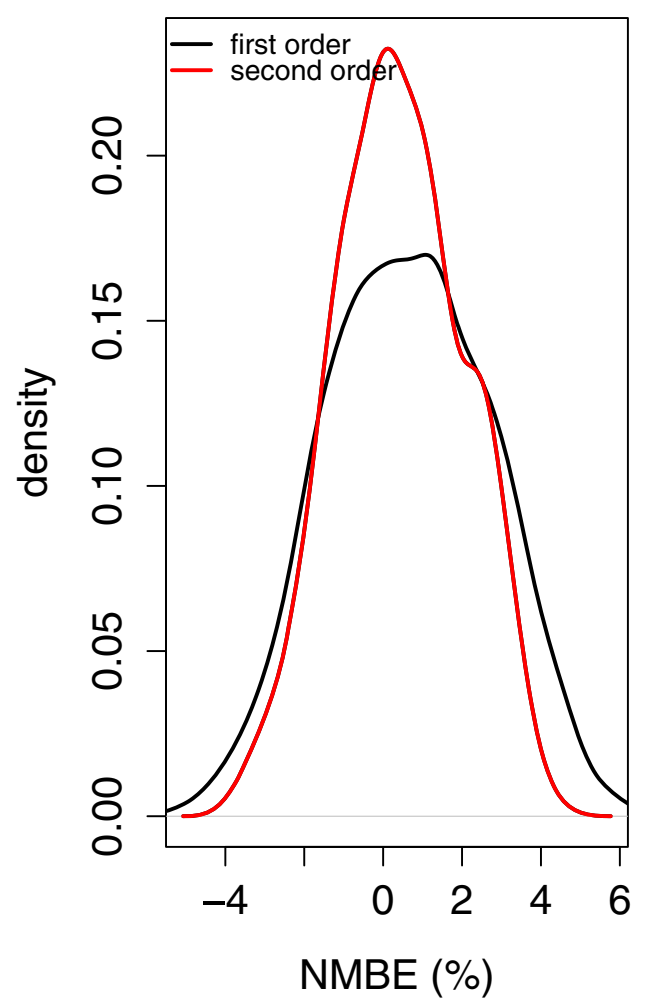

Fig. 4. BES vs. meta model: $\mathrm{NMBE}_{\mathrm{BES}, \mathrm{Mm}}$.

and 4 present the probability density function of the 1140 calculations, respectively, CVRMSEd $\mathrm{BES}, \mathrm{Mm}_{\mathrm{B}}$ and $\mathrm{NMBE}_{\mathrm{BES}, \mathrm{Mm}}$ for the two meta models.

The first and second order meta models provide similar results in terms of average NMBE (respectively 0.6 and 0.4 ) but the second order model is more precise for CVRMSE (1.9 vs. 3.1). Indeed, the second model is more detailed. 
Table 3. BES vs. meta model: average and standard deviation.

\begin{tabular}{lcr}
\hline & $\begin{array}{l}\text { First } \\
\text { order }\end{array}$ & $\begin{array}{l}\text { Second } \\
\text { order }\end{array}$ \\
\hline Number of simulations & 14 & 105 \\
NMBE $_{\text {BES,Mm }}$ average & 0.63 & 0.41 \\
NMBE $_{\text {BES,Mm }}$ standard deviation & 2.07 & 1.62 \\
CVRMSEd $_{\text {BES,Mm }}$ average & 3.12 & 1.92 \\
CVRMSEd $_{\text {BES,Mm }}$ standard & 1.13 & 1.11 \\
deviation & & \\
\hline
\end{tabular}

Table 4. Series of actions selected for the energy savings evaluation.

\begin{tabular}{lll}
\hline Scenario & Series of actions & Description \\
\hline R1 & $\mathrm{O} 1$ & Windows \\
R2 & $\mathrm{O} 2$ & Walls \\
R3 & $\mathrm{O} 1+\mathrm{O} 2$ & Windows and walls \\
R4 & $\mathrm{O} 1+\mathrm{O} 2+\mathrm{O} 3$ & Windows, walls and \\
& & ventilation \\
R5 & $\mathrm{O} 1+\mathrm{O} 3$ & Windows and ventilation \\
R6 & $\mathrm{O} 3$ & Ventilation \\
\hline
\end{tabular}

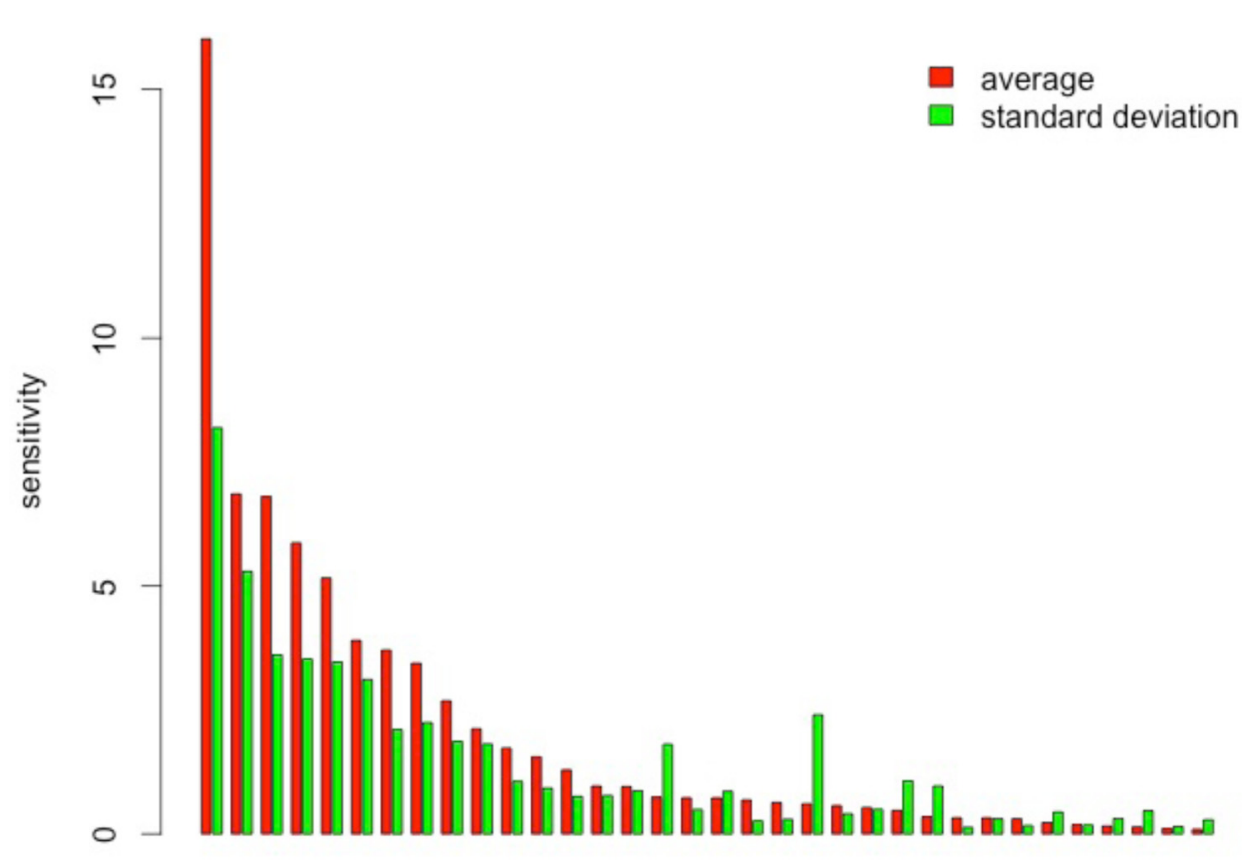

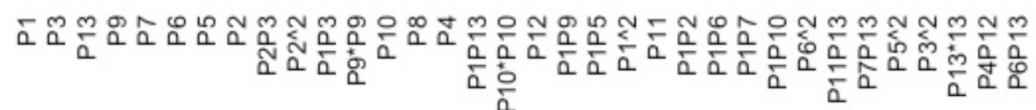

Fig. 5. Average value and standard deviation for the 34 main uncertainty indices.

Both provide results that are consistent, with an uncertainty limit between simulation and measurement prescribed by ASHRAE. In other words, the error made by using the meta model in order to evaluate simulation uncertainty is consistent with the error limit that ASHRAE prescribes (Tab. 3).

\subsection{Retrofitting operations design}

The building under study was built in the seventies. It has no insulation on the walls and the windows are quite old and should be improved, particularly because, from a practical point of view, windows are easy and fast to change. On the other hand, as the roof already presents $20 \mathrm{~cm}$ insulation, no retrofitting has been planned. Among classical works in energy retrofitting, three potential and basic actions can then be chosen such as:

- changing windows (O1);
- insulating walls (O2);

- changing ventilation system (O3).

The specifications for the new windows chosen are: $U g=1.27$ and $g=0.59$. Wall insulation is provided by $10 \mathrm{~cm}$ of glass wool. Changing the ventilation system should improve air quality and may generate additional energy savings if humidity-controlled ventilation is chosen. But as TRNSys are not very effective in considering humidity calculations, the chosen system is a system with variable flow that is reduced when the building is not occupied.

With regard to modelization in TRNsys, we consider that the uncertainty of retrofitted element characteristics is negligible compared with the uncertainty of these elements before the retrofit. The probable improvement of air tightness, which usually results from the replacement of windows, is not taken into account in this study. Then, six series of actions as a combination of elemental operations were selected (Tab. 4). 


\section{Toward a calibration}

\subsection{Uncertainty analysis}

The coefficients of the meta model (Eqs. (3) and (4)) allow for uncertainty indices of the simulation to be reached. Indeed, each coefficient represents the variability of the calculated heating demand as a function of the variability of the input parameter.

For the uncertainty analysis, Figure 5 presents the average value and standard deviation (during the year) of each coefficient. The standard deviation indicates the variability of the parameter's influence through the year.

The results are consistent with those found in the literature. The temperature setpoint $(P 1)$ provides the main sensitivity, with a coefficient two to three times higher than the second parameter. Air tightness (P3), ground temperature $(P 13)$, conduction coefficient of windows $(P 9)$, internal gains $(P 7)$, conduction coefficient of the roof $(P 6)$ and external walls $(P 5)$ have a major influence on heat load. Despite a wide range of variation, the ventilation rate $(P 2)$ comes only in the eighth position. This confirms the suitability of the choice of parameters for the meta model construction.

The linear conduction coefficient $(P 10)$ comes after, with occupancy $(P 8)$, as it finally does not occur as often (40-50 h a week) and involves only little heat compared, for example, to plug loads. Solar transmission through glass only comes afterward; it seems that the building does not absorb as much solar gains. Albedo $(P 12)$ and floor concrete thickness $(P 11)$ do not have a major influence on the model results.

In the second order, most of the main parameter interactions involve the three most influential parameters: $P 1, P 3$ and $P 13$. The main interaction corresponds to interaction between air tightness and ventilation rates, which should be easily explained with physical equations. Most of the parameter uncertainty indices also seem to vary considerably through the year.

In order to optimize the meta model construction, it would be useful to only retain the first 30 coefficients.

\subsection{Finding the optimal calibration}

As explained above, for calibration, the data from January 1, 2013 to March 19, 2013 were used. 10000 runs of the two meta models with a random draw of $P$ values in their range of variation were performed. Calculated heat loads were compared to measured ones. The NMBE condition was first taken and then the second one verified.

For the two meta models, the percentages of selected simulations that comply with the NMBE and CVRMSE conditions is about $35 \%$. Even if the two experiment designs are not as representative as the TRNsys model, the comparison with measured data generates very similar results. The verification of CVRMSE after having applied the limit on NMBE shows a CVRMSE of not much more than $14 \%$. It seems that the CVRMSE is not, in our case, the restricting indicator. This could be explained by the fact that every dynamic parameter (occupancy, plug loads, etc.) has been monitored and taken into account in the BES.

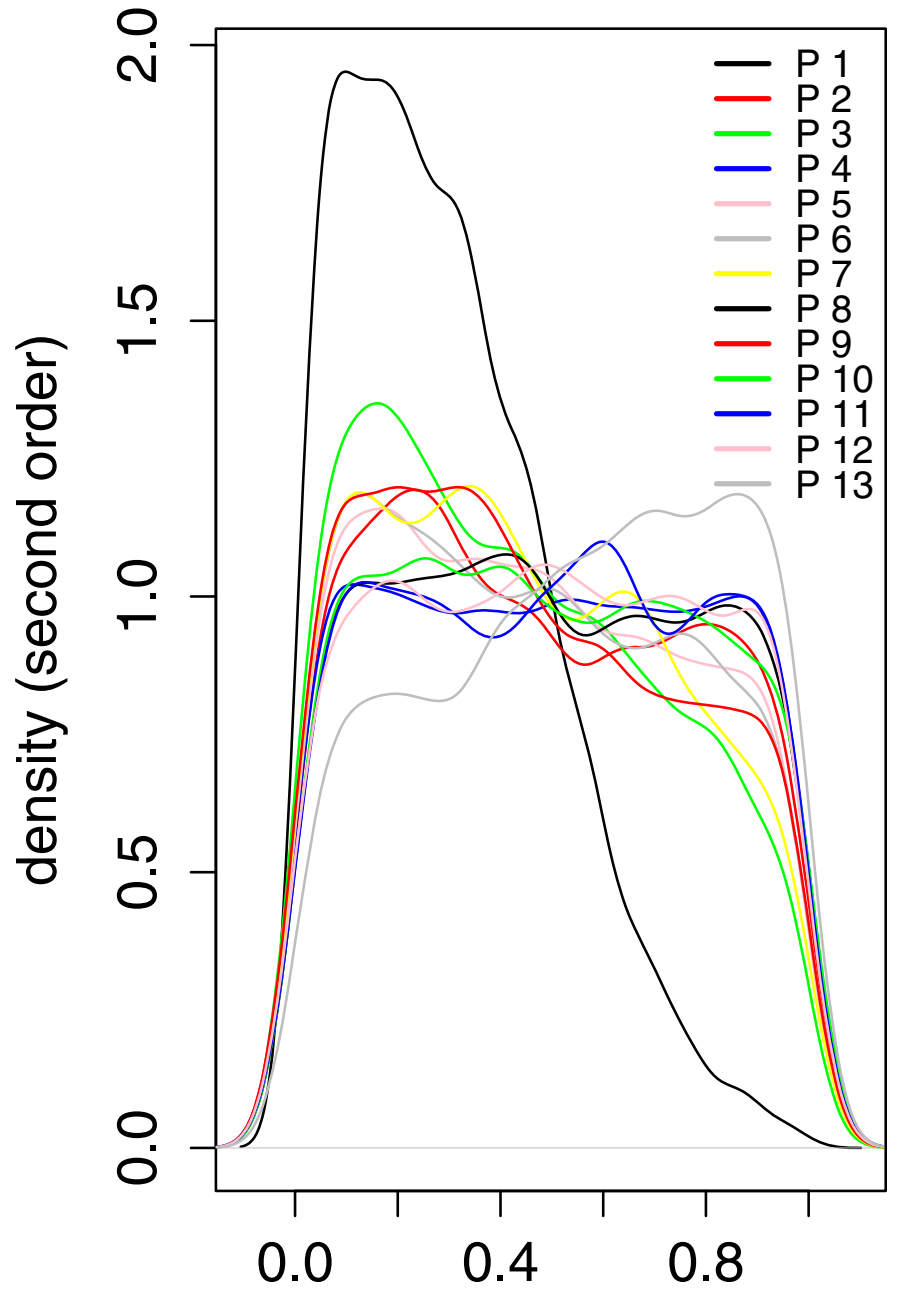

parameter value

Fig. 6. Density plot of parameter values for acceptable calibration (second order meta model).

In order to identify the values of parameters that lead to acceptable calibrations, Figure 6 represents the probability density function of the parameter values for the $35 \%$ previously selected simulation. For most of the parameters, the distribution looks like the uniform one. This shows that every value of those parameters in their range of variation allows for an acceptable calibration to be reached, which typically illustrates the under-determination of a calibration problem. It appears that only a few parameters have a real influence on acceptable calibration. Indeed, as the indoor temperature was the most influential parameter, it has a significant impact on the calibration results.

\subsection{Energy savings assessment}

The following results have been obtained with the optimized meta model, based on the 30 first influential coefficients. The six meta models, corresponding to the six series of actions, were built with the same experiment designs. Of the 10000 


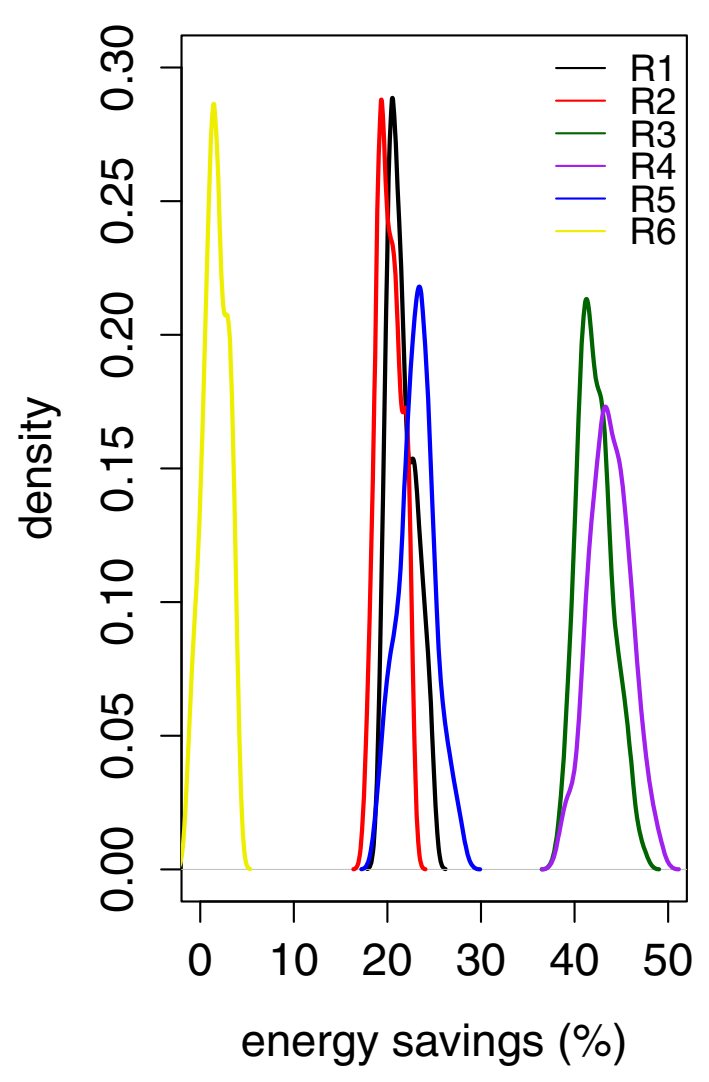

Fig. 7. Energy savings assessment density plot.

Table 5. Energy savings for each series of tasks: average value and standard deviation.

\begin{tabular}{lll}
\hline Scenario & Average & Standard deviation \\
\hline R1 & 21.5 & 1.4 \\
R2 & 20.2 & 1.2 \\
R3 & 42.2 & 1.8 \\
R4 & 43.7 & 2.2 \\
R5 & 23.1 & 1.9 \\
R6 & 1.6 & 1.3 \\
\hline
\end{tabular}

previous calculations, about 3500 were selected to assess energy savings. Figure 7 presents the density curves of the calculated energy savings for each series of actions.

Changing ventilation systems (R6) does not really improve the building's energy performance, but it is necessary for indoor air quality. Obviously, the series of actions consisting in changing windows and wall insulation (R3 and R4) provides the best results with expected savings of more than $40 \%$. It appears that changing windows (R1) and wall insulation (R2) provides quite the same results. Uncertainties on the savings appear to be quite similar: from 1.2 to 2.2 for a standard deviation (Tab. 5). The uncertainties (standard deviation) of energy savings are by the same order as the calibration ones. Then it seems that, in this case study, the energy savings calculation does not depend so much on the parameters chosen for calibration.

\section{Conclusion}

The meta model construction presented in this paper, using experimental design, provides a representation of BES with $<5 \%$ of error (CVRMSE). It is truly consistent with the use of meta models for uncertainty analyses or model calibration. As it has been applied on a fairly old building, this result must be confirmed in other case studies, including more energy-efficient buildings. It could also be applied to simulations that modelize HVAC. Then, as it only requires a few simulations for construction, it seems useful for assessing uncertainty in energy savings evaluations. This method shows that the uncertainty in energy savings seems fairly insignificant: a few percentage points compared with energy savings of $40 \%$. The problem will consist in demonstrating the reality of the savings by way of a performance verification. The use of the meta model should be helpful.

A portion of this work has been supported by the French National Research Agency (ANR) through the Habitat Intelligent et Solaire Photovoltä̈que Program (projet MEMOIRE ANR-10HABISOL-006) and by the French Ministry of Ecology.

\section{Nomenclature}

$\begin{array}{ll}\text { Symbol } & \text { Description } \\ P i & \text { parameter real value } \\ P i^{*} & \text { dimensionless parameter value in design of } \\ & \text { experiment (between } 0 \text { and 1) } \\ C_{d, k} & \text { calculated consumption for the } d \text { day and } \\ & \text { the } k \text { experiment } \\ \alpha_{d, i} & \text { coefficient of the meta model for first order } \\ \alpha_{d, i, j} & \text { coefficient of the meta model for second } \\ C_{\text {calc, }} & \text { order } \\ M_{d} & \text { matrix of calculated daily consumption } \\ P & \text { vector of meta model coefficients } \\ \text { NMBE } & \text { vector of parameters values } \\ \mathrm{CVRMSE} & \text { normalized Mean Bias Error } \\ & \text { coefficient of variation of root mean square } \\ m_{i} & \text { error } \\ s_{i} & \text { measured value for the } i \text { data point } \\ m & \text { simulated value for the } i \text { data point } \\ \mathrm{CVRMSEd} & \text { average of the measured values } \\ \mathrm{CVRMSEd} & \text { CVRMSE for a daily time step } \\ \text { Ni } & \text { daily CVRMSE between building energy } \\ \text { NME } & \text { simulation and meta model } \\ & \text { NMBE between building energy simula- } \\ & \text { tion and meta model } \\ & \text { elemental retrofitting operation } \\ & \text { retrofitting series of tasks } \\ & \text { Design of Experiment } \\ & \end{array}$

\section{References}

1. Q. Wang, S. Holmberg, A methodology to assess energy demand savings and cost effectiveness of retrofitting in existing Swedish residential buildings, Sustain. Cities Soc. 14, 254-266 (2015) 
2. V. Nik, E. Mata, A.S. Kalagasidis, A statistical method for assessing retrofitting measures of buildings and ranking their robustness against climatic change, Energy Build. 88, 262-275 (2015)

3. A. Boyano, P. Hernandez, O. Wolf, Energy demands and potential savings in European office buildings: case studies based on energyplus simulations, Energy Build. 65, 19-28 (2013).

4. T. Hong, C. Koo, J. Kin, M. Lee, K. Jeaong, A review on sustainable construction management strategies for monitoring, diagnosing, and retrofitting the building's dynamic energy performance: focused on the operation and maintenance phases, Appl. Energy 155, 671-707 (2015)

5. European Parliament of the Council, EN 15203:2005 energy performance of building - assessment of energy use and definition of energy rating, 2005

6. CSTB, Reglementation thermique 2012

7. D. Coackley, P. Raftery, M. Keane, A review of methods to match building energy simulation models to measured data, Renew. Sustain. Energy Rev. 37, 123-141 (2014)

8. S. Bertagnolio, P. Andre, Development of an evidence based calibration methodology dedicated to energy audit office buildings. Part 1: Methodology and modeling, in Proceeding of the 10th REHVA world Congress CLIMA 2010, Antalya, Turkey (2010)

9. D. Coakley, P. Raftery, P. Mollo, G. White, Calibration of detailed BES model to measured data using an evidence based analytical optimisation approach, in Proceeding of Building Simulation 2011, Sydney (2011)

10. ASHRAE, ASHRAE guideline 14, Measurement of energy and demand savings (ASHRAE, Atlanta, GA, 2002)

11. G. Mustafaraj, F. Marini, A. Costa, M. Keane, Model calibration for building energy efficiency simulation, Appl. Energy 130, 72-85 (2014)

12. M. Manfred, N. Aste, R. Moshksar, Calibration and uncertainty analysis for computer models - a meta model based approach for integrated building energy simulation, Appl. Energy 103, 627-641 (2013)

13. B. Eisenhower, Z. O'Neil, S. Narayanan, V. Fonoberov, I. Mezic, A methodology for meta-model based optimization in building energy models, Energy Build. 47, 292-301 (2012)

14. R. Rabenstein, Application of model reduction techniques to building energy simulation, Solar Energy 53, 289-299 (1994)

15. M. Gouda, S. Danaher, C. Underwood, Building thermal reduction using non linear constrained optimization, Build. Environ. 37, 1255-1265 (2002)

16. Z. Ma, P. Cooper, D. Daly, L. Ledo, Existing building retrofits: methodology and state of the art, Energy Build. 55, 889-902 (2012)
17. C. Spitz, Analyse de la fiabilite des outils de simulation et des incertitudes de metrologie appliquee a l efficacite energetique des batiments, $\mathrm{PhD}$ thesis, University de Grenoble, 2012

18. H. Brohus, P. Heiselberg, A. Simonsen, K. Sorensen, Uncertainty of energy consumption of domestic buildings, in Proceeding of Building Simulation 2009, Glasgow (2009), pp. 1022-1029

19. D. Daly, P. Cooper, Z. Ma, Understanding the risk and uncertainties introduced by common assumptions in energy simulations for Australian commercial buildings, Energy Build. 75, 382-393 (2014)

20. X. Corrado, Uncertainty and sensitivity analysis for building energy rating, J. Build. Phys. 33, 125-156 (2009)

21. J. Goffart, Impact de la variabilite des donnees meteorologiques sur une maison basse consommation. application des analyses de sensibilite pour des entrees temporelles, $\mathrm{PhD}$ thesis, University de Grenoble, 2013

22. J. Goffart, E. Wurtz, G. Sauce, T. Bejat, Impact and source of uncertainties in high efficiency building simulation: some examples, in Proceeding of Building Simulation 2011, Sydney (2011), pp. 2822-2827

23. J. Robertson, B. Polly, J. Collis, Reduced order modeling and simulated annealing optimization for efficient residential building with utility bill calibration, Appl. Energy 148, 169-177 (2015)

24. S. Vivier, Strategies d'optimisation par la methode des plans d'experiences et application aux dispositifs electrotechniques modelises par elements finis, Ph.D. thesis, Université des sciences et technologies de Lille, 2002

25. IPMVP, ed., International Performance Measurement and Verification Protocol Concepts and Options for Determining Energy and Water Savings (US Department of Energy, DOE/ GO-102002-1554, 2002), Vol. 1

26. A. Caucheteux, A. Es-Sabar, V. Boucher, Occupancy measurement in building: a literature review, application on an energy efficiency research demonstrated building, Int. J. Metrol. Qual. Eng. 4, 135-144 (2013)

27. Solar-Energy, TRNsys v17 a TRaNsient System Simulation program, 2009

28. TE, TRNbuilt (v 2.0 for TRNsys 17), 2010

29. NISTEL, Contam V 3, 2006

30. A. Persily, Myths about building envelopes, ASHRAE J. March, 39-45 (1999)

31. F. Titikpina, A. Charki, A. Caucheteux, D. Bigaud, Uncertainty assessment in building energy performance with a simplified model, Int. J. Metrol. Qual. Eng. 6, 308 (2015)

Cite this article as: Antoine Caucheteux, Antoine Gautier, Rofaïda Lahrech, A meta model-based methodology for an energy savings uncertainty assessment of building retrofitting, Int. J. Metrol. Qual. Eng. 7, 402 (2016) 